This item was submitted to Loughborough's Research Repository by the author.

Items in Figshare are protected by copyright, with all rights reserved, unless otherwise indicated.

\title{
Non-evaporative effects of a wet mid layer on heat transfer through protective clothing
}

PLEASE CITE THE PUBLISHED VERSION

http://dx.doi.org/10.1007/s00421-007-0629-y

PUBLISHER

(C) Springer Verlag

VERSION

AM (Accepted Manuscript)

LICENCE

CC BY-NC-ND 4.0

\section{REPOSITORY RECORD}

Broede, Peter, George Havenith, Xiaoxin Wang, Victor Candas, Emiel A. den Hartog, Barbara Griefahn, Ingvar Holmer, et al.. 2019. "Non-evaporative Effects of a Wet Mid Layer on Heat Transfer Through Protective Clothing". figshare. https://hdl.handle.net/2134/9295. 
This manuscript was published by the European Journal of Applied Physiology in the special issue on Environmental Ergonomics, doi: 10.1007/s00421-007-0629-y

\section{Non-evaporative effects of a wet mid layer on heat transfer through protective clothing}

Peter Bröde ${ }^{1, \bigotimes}$, George Havenith ${ }^{2}$, Xiaoxin $\mathrm{Wang}^{2}$, Victor Candas ${ }^{3}$, Emiel A. den Hartog $^{4}$, Barbara Griefahn ${ }^{1}$, Ingvar Holmér ${ }^{5}$, Kalev Kuklane ${ }^{5}$, Harriet Meinander ${ }^{6}$, Wolfgang Nocker ${ }^{7}$, Mark Richards ${ }^{8}$

${ }^{1}$ Leibniz Research Centre for Working Environment and Human Factors at the University of Dortmund (IfADo), Ardeystr. 67, D-44139 Dortmund, Germany

${ }^{2}$ Environmental Ergonomics Research Group, Department of Human Sciences, Loughborough University, Loughborough, LE11 3TU, UK

${ }^{3}$ Centre d'Etudes de Physiologie Appliquée - UPS 858 CNRS, Strasbourg, France

${ }^{4}$ Business Unit Human Factors, TNO Defence, Security and Safety, Soesterberg, The Netherlands

${ }^{5}$ Department of Design Sciences, Faculty of Engineering, Lund University, 22100 Lund, Sweden

${ }^{6}$ SmartWearLab, Tampere University of Technology, Tampere, Finland

${ }^{7}$ W.L. Gore \& Associates GmbH, Putzbrunn, Germany

${ }^{8}$ Empa, Swiss Federal Laboratories for Materials Testing and Research, CH-9014 St Gallen, Switzerland

$\triangle$ Corresponding author:

Peter Bröde

Phone: +49 2311084225

Fax: +49 2311084400

broede@ifado.de

http://www.ifado.de

The content of this manuscript was presented at the International Conference on Environmental Ergonomics 2007. 


\section{Abstract}

In order to assess the non-evaporative components of the reduced thermal insulation of wet clothing, experiments were performed with a manikin and with human subjects in which two layers of underwear separated by an impermeable barrier were worn under an impermeable overgarment at $20{ }^{\circ} \mathrm{C}, 80 \% \mathrm{RH}$ and $0.5 \mathrm{~ms}^{-1}$ air velocity. By comparing manikin measurements with dry and wetted mid underwear layer, the increase in heat loss caused by a wet layer kept away from the skin was determined, which turned out to be small $\left(5-6 \mathrm{Wm}^{-2}\right)$, irrespective of the inner underwear layer being dry or wetted, and was only one third of the evaporative heat loss calculated from weight change, i.e. evaporative cooling efficiency was far below unity.

In the experiments with 8 males, each subject participated in two sessions with the mid underwear layer either dry or wetted, where they stood still for the first 30 minutes and then performed treadmill work for 60 minutes. Reduced heat strain due to lower insulation with the wetted mid layer was observed with decreased microclimate and skin temperatures, lowered sweat loss and cardiac strain. Accordingly, total clothing insulation calculated over the walking period from heat balance equations was reduced by $0.02 \mathrm{~m}^{2}{ }^{\circ} \mathrm{C} \mathrm{W}^{-1}(16 \%)$, while for the standing period the same decrease in insulation, representing 9\% reduction only showed up after allowing for the lower evaporative cooling efficiency in the calculations. As evaporation to the environment and inside the clothing was restricted, the observed small alterations may be attributed to the wet mid layer's increased conductivity, which, however, appears to be of minor importance compared to the evaporative effects in the assessment of the thermal properties of wet clothing.

Keywords: moisture, clothing insulation, conduction, skin temperature, sweating 


\section{Introduction}

Wet clothing can increase the wearer's heat loss by increasing the thermal conductivity increasing the 'dry' heat loss (Chen et al. 2003), and by evaporation from the surface or within the clothing, possibly combined with increased condensation in outer layers (Lotens et al. 1995). These mechanisms occur simultaneously and their separate quantification in the framework of heat balance analysis is problematic as evaporative cooling efficiency, defined as the ratio of the observed evaporative cooling to the effect expected from clothed mass loss (Havenith et al. 2007b), may deviate from unity with protective clothing (Nunneley 1989; McLellan et al. 1996; Candas et al. 2006; Havenith et al. 2006, 2007a). This may lead to complications in the course of predicting unwanted cooling effects of sweat accumulated inside clothing while or after working in the cold (Meinander et al. 2004) or when modelling the sweating response of persons performing heavy work with protective clothing (Cheuvront et al. 2007).

There have been several approaches to overcome the difficulties in assessing the increased heat loss with wet clothing in the context of heat balance calculations, e.g. Aoyagi et al. (1996) adapted the skin-core temperature weighting used in the calculation of body heat storage, while assuming an unchanged clothing insulation, Chen et al. (2003) calculated changes in dry heat loss with wet clothing from measurements with a sweating manikin assuming unity evaporative cooling efficiency, while Cheuvront et al. (2007) showed that allowing for the clothing insulation to change during modelling the sweating response of clothed persons improved the predictive capabilities of the model. To provide data and models for the systematic assessment of the effects of moisture on the thermal properties of protective clothing was one major concern of the European research initiative THERMPROTECT (Havenith et al. 2005).

In a recent paper, Havenith et al. (2007a) presented a detailed analysis of the aspects related to evaporative heat loss while wearing protective clothing, especially the attenuated efficiency of evaporation (Craig and Moffitt 1974; Aoyagi et al. 1996; McLellan et al. 1996) and the internal vapour transfer accompanied with evaporation-condensation cycles in the clothing layers that on the other side may lead to higher heat losses than expected, particularly when wearing an impermeable outer layer (Candas et al. 2006, Havenith et al. 2006, 
2007b). One unresolved issue pertained to the magnitude of the decrease in clothing insulation caused by the increased conductivity of the wet textiles. Concentrating on the non-evaporative, i.e. conductive effects, this paper describes experiments performed with a manikin and with humans in which two layers of underwear separated by a layer with low vapour permeability were worn under an impermeable overgarment. Wetting the mid underwear layer beneath an impermeable outerwear should facilitate the observation of conductive effects with only minimal influence by evaporation through and from the outer clothing.

\section{Methods}

In order to reduce the evaporation to the environment, the experiments were carried out under a high humidity condition with air temperature $\left(\mathrm{T}_{\mathrm{a}}\right)$ of $20^{\circ} \mathrm{C}$, relative humidity $(\mathrm{RH})$ of $80 \%$, yielding ambient water vapour pressure $\left(\mathrm{P}_{\mathrm{a}}\right)$ of $1.87 \mathrm{kPa}$, and air velocity of $0.5 \mathrm{~ms}^{-1}$. Globe temperature was equal to $\mathrm{T}_{\mathrm{a}}$. Manikin measurements were performed at Loughborough University and human tests at IfADo.

\section{Manikin experiments}

Heat loss was measured using a thermal manikin 'Newton' (MTNW, Seattle, USA) with 32 independent zones in which surface temperature was controlled at $34{ }^{\circ} \mathrm{C}$ and the total heat input required to achieve this was accurately measured. This heat input is a direct measure of the heat loss from the manikin. As skin temperatures were uniform, clothing insulation related to this heat loss was calculated by applying the 'parallel' method (ISO 9920 2007, ISO 15831 2004). As this paper intends to study the effect of clothing, all manikin data in this paper were calculated for the clothed area $\left(\mathrm{A}_{\mathrm{c}}=1.457 \mathrm{~m}^{2}\right)$ only, excluding head, hands and feet.

Two layers of cotton (CO, type "Gnägi”, Switzerland) underwear were used, as shown in the electronic supplementary material for this paper (ESM 1a). Each layer had a separate shirt and long legged pants. The two layers were separated by a layer of Tyvek ${ }^{\circledR}$ (DuPont, Luxembourg), which prevented wicking of the moisture between layers but did allow some evaporative exchange. As the outer layer an impermeable coverall was used which was custom-made of PVC and possessed a waist band, that was tightened, and was sealed by a zipper at the front 
and Velcro fasteners at ankles, wrists and along the front up to the collar. Experiments were carried out wetting either the inner ('wet-dry') or outer ('drywet') CO layer with $600 \mathrm{~g}$ of water, and additional measurements were done with both layers either dry ('dry-dry') or wet ('wet-wet').

For the conditions with wet $\mathrm{CO}$, the shirt and pants were separately pre-wetted with $300 \mathrm{~g}$ water each and kept in sealed bags at room temperature for about 12 hours before the experiment in order to distribute the moisture. The amount of water evaporated from the clothing $\left(\mathrm{m}_{\mathrm{e}}, \mathrm{g}\right)$ was determined by weighing the garments before and after each measurement (Sartorius balance $150 \mathrm{~kg}, \pm 1 \mathrm{~g}$ ). Evaporative heat loss was then calculated as $\lambda \times\left(\mathrm{m}_{\mathrm{e}} \times \Delta \mathrm{t}^{-1}\right) \times \mathrm{A}_{\mathrm{c}}^{-1}$ with $\Delta \mathrm{t}$ denoting measurement time (s) and $\lambda=2430 \mathrm{~J} \cdot \mathrm{g}^{-1}$ (enthalpy of evaporation). All measurements lasted 40 minutes and were performed twice. The means of the two measurements are reported for the results.

\section{Human experiments}

\section{Subjects and study design}

Eight healthy male students (Mean \pm SD: age $22.8 \pm 1.3$ yrs, body height $1.81 \pm$ $0.06 \mathrm{~m}$, body mass $\left(\mathrm{m}_{\mathrm{b}}\right) 75.1 \pm 6.6 \mathrm{~kg}$, body surface area $\left.\left(\mathrm{A}_{\mathrm{D}}\right) 1.94 \pm 0.11 \mathrm{~m}^{2}\right)$, gave written consent into participation in two trials each, that had been approved by IfADo's Ethics Committee. The subjects wore their own briefs, socks and sport shoes, and a four layer clothing ensemble as shown in the electronic supplementary material (ESM 1b) that was slightly changed compared to the manikin study and comprised polypropylene underwear (HHS, Helly Hansen Super Bodywear ${ }^{\circledR} 140 \mathrm{~g} / \mathrm{m}^{2}$ ), followed by a hooded Tychem ${ }^{\circledR}$ C Standard coverall (DuPont, Luxembourg) as intermediate layer, that prevented both wicking and evaporation, and the same additional CO mid layer and impermeable PVC outer layer as used with the manikin. The area clothing factor $\left(f_{c l}\right)$ was obtained as the ratio of pixels of digital photographs taken from the front and the side of the fully clothed to those of the nude (only briefs wearing) subject (McCullough et al. 2005), and amounted to $1.32 \pm 0.04$. Trials were performed with the CO mid layer either dry or wetted with $618 \pm 16 \mathrm{~g}$ of water. In the wetted $\mathrm{CO}$ condition, the cotton clothing was wetted by applying a rinsing and spin-cycle programme of a washing machine. If the necessary amount of water was not 
reached, the cotton clothes were additionally sprayed with water. The sequence of the two conditions was balanced across subjects who visited the laboratory at the same time of day, with intervals between the 2 visits ranging from 1 to 19 days, the median interval was 4 days.

Following a resting period of 30 minutes, each session consisted of 3 phases inside a climatic chamber, each lasting 30 minutes and separated by a 3 minute period where the fully clothed person's weight was determined (Mettler-Sauter balance, Mettler, Germany, $\pm 5 \mathrm{~g})$, yielding the mass loss due to evaporation $\left(\mathrm{m}_{\mathrm{e}}\right)$ for that bout. Phase 1 comprised of 2 minutes of treadmill walking $(4.5 \mathrm{~km} / \mathrm{h}$ on the level) for initial moisture and temperature distribution inside the clothing followed by a 28 minutes lasting standing period in order to minimise sweat production. In phases 2 and 3 the persons had to perform the treadmill work for the whole time.

\section{Measurements}

By weighing (Mettler ID1, Mettler-Toledo GmbH, Germany, $\pm 1 \mathrm{~g}$ ) the nude persons and each part of the clothing before and after the experiment, the sweat loss and the amount of moisture absorbed by the clothing was measured. Metabolic heat production $\left(\mathrm{M}, \mathrm{W} \cdot \mathrm{m}^{-2}\right.$ ) was calculated according to ISO 8996 (2004) from the analyses of $\mathrm{O}_{2}$ consumption (Servomex Series 1100, Servomex Ltd., UK) and $\mathrm{CO}_{2}$ production (UNOR Infrarot-Gasanalysator, Maihak AG, Germany) of expired air collected with Douglas bags during the last 10 minutes of phase 1 and 3, respectively.

Heart rates (HR) were determined from the electrocardiogram (Polar Tester, Polar Elektro GmbH, Germany) and rectal temperatures $\left(\mathrm{T}_{\mathrm{re}}\right)$ were continuously recorded with a flexible thermistor probe at a depth of $10 \mathrm{~cm}$ from the anal sphincter (YSI 401, Yellow Springs, USA). Mean skin temperatures $\left(T_{\text {sk }}\right)$ were calculated as area weighted average from recordings with thermistors (YSI 427, Yellow Springs, USA) that were fixed with a porous adhesive non-woven fabric (Fixomull ${ }^{\circledR}$ stretch, Beiersdorf, Germany) at 8 body sites according to a scheme slightly modified from ISO 9886 (1992) (forehead, left chest, right frontal thigh, left dorsal thigh (instead of calf), right scapula, right upper arm, left lower arm, left hand). 
Relative humidity $\left(\mathrm{RH}_{\mathrm{mc}}\right)$ and air temperature $\left(\mathrm{T}_{\mathrm{mc}}\right)$ in the clothing's microclimate were measured by data loggers (HandyLog DK502, Driesen+Kern GmbH, Germany) positioned at the right chest and left scapula between the HHS and Tychem ${ }^{\circledR}$ layer and, correspondingly, at the contra lateral sites between the $\mathrm{CO}$ mid and PVC outer layer. Partial water vapour pressure $\left(\mathrm{P}_{\mathrm{mc}}\right)$ was computed from $\mathrm{T}_{\mathrm{mc}}$ and $\mathrm{RH}_{\mathrm{mc}}$ according to DIN 50010-2 (1981). Averages of the values at the chest and scapula were calculated as the results for each layer. Surface temperatures on the inner and outer side of the PVC outerwear were measured as averaged recordings of thermistors (YSI 427, Yellow Springs, USA) taped on 6 locations corresponding to the six body sites covered by clothing (i.e. without forehead and hand) used for $\mathrm{T}_{\mathrm{sk}}$ registration.

Using standardised scales (ISO 10551 1995) the subjects rated their thermal sensation (TS, -4: 'very cold' to 4: 'very hot'), thermal preference (TP, -3: 'much warmer' to 3: 'much cooler') and thermal tolerance (TT, 1: 'perfectly bearable' to 5: 'unbearable'). They gave ratings for moisture sensation (MS) on a five-pointscale (1: 'dry', 2: 'slightly moist', 3: 'moist', 4: 'wet', 5: 'very wet') and rated perceived exertion (RPE) using Borg's 15-point-scale with values ranging from 6: 'no exertion at all' to 20: 'maximal exertion' (Borg 1998). Votes were obtained at the end of the resting period, at the start of the experiment and at the end of each phase.

\section{Procedure}

After arriving at the institute, the subject's nude weight was taken as was the weight of the different clothing pieces in a preparation room. The subject inserted the rectal probe and was equipped with the skin temperature sensors except at the forehead and hand. Then he put on the HHS underwear and rested lying on a bed in a room with neutral temperature $\left(22-23^{\circ} \mathrm{C}\right)$ for 30 minutes. Meanwhile the outer PVC layer was equipped with the sensors for measuring the inside surface temperature. The wet clothing's weight was taken immediately before it was donned onto the person who was meanwhile clothed with the Tychem ${ }^{\circledR}$ layer and equipped with the humidity sensors (ESM 1b, electronic supplementary material). Finally, the PVC outer layer was donned and the remaining sensors were taped. With dry CO mid layer, the subject's preparation took place in the preparation room $\left(22-23{ }^{\circ} \mathrm{C}\right)$. With wet $\mathrm{CO}$ layer, donning the three outer layers was carried 
out in the climatic chamber with the high humidity and the air velocity temporarily reduced to $0.2 \mathrm{~ms}^{-1}$ to avoid evaporation as far as possible. When the subject was fully equipped, the protocol was carried out as described above. After the end of the experiment the sensors and clothing were removed from the subject and weighing of the nude subject, clothing and equipment, as well as data storage was carried out.

\section{Calculations and statistics}

All heat balance components were computed in units of $\mathrm{W} \cdot \mathrm{m}^{-2}$. Body heat storage (S) was calculated as $\left(\Delta \mathrm{T}_{\mathrm{b}} \times \Delta \mathrm{t}^{-1}\right) \times \mathrm{m}_{\mathrm{b}} \times \mathrm{A}_{\mathrm{D}}^{-1} \times \mathrm{c}_{\mathrm{p}}$ with $\Delta \mathrm{T}_{\mathrm{b}} \times \Delta \mathrm{t}^{-1}$ $\left({ }^{\circ} \mathrm{C} \cdot \mathrm{s}^{-1}\right)$ denoting the rate of change of body temperature, that was computed from $\mathrm{T}_{\mathrm{re}}$ and $\mathrm{T}_{\mathrm{sk}}$ applying a 4:1 weighting, over the final 5 minutes of each phase, and $\mathrm{c}_{\mathrm{p}}=3.48 \mathrm{~kJ} \cdot \mathrm{kg}^{-1} \cdot{ }^{\circ} \mathrm{C}^{-1}$ the specific heat of body tissue. The respiratory heat loss components were estimated by $1.516 \times 10^{-3} \times \mathrm{M} \times\left(28.56+0.641 \times \mathrm{P}_{\mathrm{a}}-0.885 \times \mathrm{T}_{\mathrm{a}}\right)$ for the convective $\left(\mathrm{C}_{\text {resp }}\right)$, and by $1.27 \times 10^{-3} \times \mathrm{M} \times\left(59.34-11.63 \times \mathrm{P}_{\mathrm{a}}+0.53 \times \mathrm{T}_{\mathrm{a}}\right)$ for the evaporative $\left(\mathrm{E}_{\text {resp }}\right)$ fraction, respectively (Malchaire et al. 2001). Evaporative heat loss (E) corrected for respiratory loss was then computed as $\lambda \times\left(\mathrm{m}_{\mathrm{e}} \times \Delta \mathrm{t}^{-1}\right) \times \mathrm{A}_{\mathrm{D}}^{-1}-\mathrm{E}_{\text {resp }}$. By solving the heat balance equation for the added up conductive, radiatitive and convective components, and assuming zero external work for walking and standing on the level, the 'Dry' heat loss was computed as $\mathrm{M}-\mathrm{S}-\mathrm{E}-\mathrm{E}_{\text {resp }}-\mathrm{C}_{\text {resp }}$, and was used to calculate total clothing insulation $\left(\mathrm{I}_{\mathrm{t}}, \mathrm{m}^{2} \cdot{ }^{\circ} \mathrm{C} \cdot \mathrm{W}^{-1}\right)$ by $\left(\mathrm{T}_{\mathrm{sk}}-\mathrm{T}_{\mathrm{a}}\right) \times \operatorname{Dry}^{-1}$. The continuously recorded variables were averaged over 5 minute intervals and presented as means and SD for the dry and wet CO mid layer conditions. Differences between the two conditions in the values at the end of phase 1 (standing) and phase 3 (walking) were tested for statistical significance using a paired-comparison t-test. 


\section{Results}

\section{Manikin experiments}

The averaged $\mathrm{T}_{\mathrm{a}}$ and $\mathrm{RH}$ during the manikin study were $20.4{ }^{\circ} \mathrm{C}$ and $76 \%$, respectively. The total manikin heat losses measured in the experimental conditions are summarised in Figure 1, also presenting the increase in heat loss from the condition dry-dry compared to the evaporative heat loss calculated from $m_{e}$, the latter is shown together with the weight change of the different clothing layers in Figure 2.

Wetting the outermost CO layer caused similar increases in heat loss, in $\mathrm{m}_{\mathrm{e}}$, and consequently in the calculated evaporative loss, irrespective of the condition of the inner CO layer: increases were $5.7 \mathrm{~W} \cdot \mathrm{m}^{-2}, 25.0 \mathrm{~g}$ and $17.4 \mathrm{~W} \cdot \mathrm{m}^{-2}$, respectively, with the inner $\mathrm{CO}$ layer being dry, and $5.1 \mathrm{~W} \cdot \mathrm{m}^{-2}, 23.5 \mathrm{~g}$ and 16.3 $\mathrm{W} \cdot \mathrm{m}^{-2}$, respectively, with wet inner CO.

For the dry-wet condition the heat loss increase from the manikin was only $33 \%$ of the evaporative heat loss from the ensemble as calculated from the mass loss of the clothed manikin. Assuming a greater conduction of the wet $\mathrm{CO}$ layer as compared to dry, this means that more than two thirds of the actual evaporative heat was drawn from the environment and less than one third from the skin. For the wet-dry condition on the other hand, the increase in heat loss from the skin compared to dry was actually higher $(142 \%)$ than the total clothing evaporative heat loss. Though $\mathrm{m}_{\mathrm{e}}$, the loss to the environment, was similar (28.5 $\mathrm{g}$ in wet-dry versus $25 \mathrm{~g}$ in dry-wet), moisture loss from the wet CO layer was higher (121 $\mathrm{g}$ in wet-dry versus $74 \mathrm{~g}$ in dry-wet) with most of the difference being transferred to the outer CO layer (Figure 2). As wicking was limited by the interlayer, this implies that part of the moisture, that evaporated from the inner underwear taking up the latent heat of evaporative cooling, has condensed again in the outer layers, consequently releasing heat. Thus heat loss by evaporation was higher than calculated based on the total clothing weight change. When considering only the inner layer's weight loss, $\left(121 \mathrm{~g}\right.$ corresponding to $\left.84 \mathrm{~W} \cdot \mathrm{m}^{-2}\right)$ one can indeed see that this has not all contributed to the total body heat loss increase $\left(28.2 \mathrm{~W} \cdot \mathrm{m}^{-2}\right)$ due to heat being released by condensation in the outer layers. This, in turn, may 
have increased the temperature of the outer layers, and thus the total dry heat loss to the environment.

In the wet-wet condition the increased heat loss came close to the calculated evaporative heat loss $(92 \%)$ and appeared to be the sum of the dry-wet and wetdry condition.

\section{Human experiments}

\section{Sweating and moisture in clothing}

The sweat production, the distribution of moisture in the different clothing layers after the experiment and the clothed mass loss during the three 30 minute periods for the two experimental conditions are presented in Table 1. Sweating was significantly reduced with the wet $\mathrm{CO}$ mid layer by about one third compared to the dry $\mathrm{CO}$ condition, and consequently, the amount of moisture absorbed by the HHS underwear located next to the skin was significantly lower. This led to a reduced difference in averaged total moisture content between the two conditions from $618 \mathrm{~g}$ at the start to $455 \mathrm{~g}$ after the experiment. The Tychem ${ }^{\circledR}$ layer served as an effective barrier against moisture transport, as was indicated by the low amount of sweat that was transferred from the HHS layer into the $\mathrm{CO}$ and PVC layers in the dry $\mathrm{CO}$ condition. With wet $\mathrm{CO}$ there was significantly more moisture absorbed by the PVC outer layer.

The clothed mass loss to the environment was low while standing, was approximately doubled in the first and increased to its threefold value in the second walking period, but there were no significant differences between the two CO conditions.

\section{Clothing microclimate}

The air temperature and humidity recordings, presented in Figure 3, revealed differing patterns for the HHS/Tychem ${ }^{\circledR}$ layer \#1-2 and the CO/PVC layer \#3-4, respectively. In the HHS/Tychem ${ }^{\circledR}$ layer located nearer to the skin, the $\mathrm{RH}_{\mathrm{mc}}$ profiles were similar for both conditions, but $\mathrm{T}_{\mathrm{mc}}$ was significantly lower with wet $\mathrm{CO}$ in both the standing and walking phase (Table 2), which also resulted in lower $\mathrm{P}_{\mathrm{mc}}$. In the mid $\mathrm{CO} / \mathrm{PVC}$ outer layer, $\mathrm{T}_{\mathrm{mc}}$ was very similar, but $\mathrm{RH}_{\mathrm{mc}}$ was definitely higher in the wetted layer, and consequently also $\mathrm{P}_{\mathrm{mc}}$. The nearly 
constant values for $\mathrm{RH}_{\mathrm{mc}}$ in the HHS/Tychem ${ }^{\circledR}$ layer during the static phase indicate the expected low amount of sweat produced while standing still. With walking, humidity increased indicating the onset of more heavily sweating. The surface temperatures of the PVC outer layer increased during the walking period and were lower inside than at the outside, but differed not much between the two experimental conditions while standing (Table 2). Only at the end of the walking period there was a tendency to a higher inside temperature with the wet CO layer.

\section{Heart rates, rectal and skin temperatures, metabolic rate}

Figure 4 shows the development of $\mathrm{HR}, \mathrm{T}_{\mathrm{re}}$ and $\mathrm{T}_{\mathrm{sk}}$ during the experiments. HR were approximately constant while standing with only minor differences between the two experimental conditions, but increased during walking to significant lower values at the end of experiment in the wet condition (Table 2), although the metabolic rates were nearly identical in both conditions with average values of about $60 \mathrm{~W} \cdot \mathrm{m}^{-2}$ while standing and $175 \mathrm{~W} \cdot \mathrm{m}^{-2}$ while walking (Table 3 ). $\mathrm{T}_{\mathrm{re}}$ was also constant while standing and increased under treadmill work, but the time profiles were very similar in both conditions. $T_{\text {sk }}$ was significantly lower throughout the whole session for the condition with wet CO mid layer (Table 2). Considering the local skin temperatures, this was only observed at those sites covered by the clothing, not at the forehead and hand.

\section{Subjective responses}

Mean and SD of the subjective ratings at the end of the first and third phase are presented in Table 2. Starting from 'neutral', 'dry' and 'no exertion' values for TS, MS and RPE, respectively, at the end of the resting period, they increased slightly with the start of the experiment, remained constant during the static phase and increased with time during the walking phase. TS was significantly less warm with the wet $\mathrm{CO}$ layer while standing though at the end of experiment the difference to the 'dry' condition was smaller and not significant. Corresponding results were obtained for TP, whereas TT showed less tolerance to the dry CO condition at the end of the experiment. Contrary to that, there was no significant difference between the two conditions with respect to the time profiles for MS and 
RPE, especially MS ratings were nearly identical notwithstanding the amount of water that had been applied to the $\mathrm{CO}$ mid layer.

\section{Heat balance}

The partition of the metabolic heat production into heat storage and the different avenues of heat loss as well as the total clothing insulation calculated from dry heat loss is presented in Table 3 for the standing and last walking period, respectively. As expected, the absolute values of all heat balance components increased while walking. There were no significant differences between the dry or wet $\mathrm{CO}$ condition observable while standing, but at the end of the walking period $\mathrm{S}$ was significantly higher with dry $\mathrm{CO}$, whereas it did not differ significantly from zero with wet $\mathrm{CO}$, indicating that a steady state was reached only for the latter condition. E, based on mass loss of the clothed person did not differ for the two conditions.

$\mathrm{I}_{\mathrm{t}}$ was significantly reduced by $16 \%$ with wet CO compared to dry CO during walking, but there was no significant difference in the standing period. $\mathrm{I}_{\mathrm{t}}$ while walking was reduced to $50 \%$ of that while standing for dry $\mathrm{CO}$, and to $41 \%$ for wet CO.

\section{Discussion}

\section{Manikin measurements}

The manikin experiments demonstrated small increases in heat loss, i.e. small reductions of clothing insulation by a wet layer that was kept from the skin by an impermeable layer, presumably mainly due to increased conductive heat loss. The greater increase in heat loss for the wet-dry condition may have several reasons, that are all related to the fact that the utilised Tyvek ${ }^{\circledR}$ mid layer did not fully prevent water vapour transfer into the outer layers. Firstly, as evaporation takes place close to the skin, the heat loss is more effective in cooling the skin. Secondly, as the separating layer did not prevent evaporation entirely and due to the higher temperature of the wet layer, internal vapour transfer occurred. Thirdly, condensation of the evaporated moisture in the outer layers, caused the outer layers to heat up and increased the total heat loss. All this led to a higher increase in heat loss than expected from weight change, i.e. to an evaporative cooling 
efficiency above unity, as it had been observed also in other studies with impermeable clothing (Lotens et al. 1995, Candas et al. 2006, Havenith et al, 2006, 2007b).

On the other hand, when the outer CO layer was wetted, the increase in heat loss was only about one third of that expected from weight change, irrespective whether the condition with dry or wet inner CO layer was chosen as reference. Further experiments during THERMPROTECT have shown that this attenuation in evaporative efficiency seems to depend on the location of the wet layer, as higher efficiencies (about 70\%) were observed when wetting the layer next to the skin (Havenith et al. 2007a), and lower efficiencies (about 25\%) were obtained when the outer layer was wetted (Havenith et al. 2005).

With both CO layers being wet, which might simulate the situation with all layers wetted by sweating, these two effects, one increasing and the other attenuating heat loss, appear to cancel out and efficiency was nearly unity for this special clothing ensemble under the thermal conditions used.

\section{Human measurements}

A picture of reduced heat strain due to reduced clothing insulation by a wetted mid layer was observed in a number of parameters in the human trials. The most marked reaction was a reduced temperature of the clothing layer adjoining the skin and a concomitant reduction of skin temperature. Correspondingly, the wet CO condition was assessed as less warm by the subjects, especially while they were standing still. This was accompanied by a lower increase in heart rate during walking, although metabolic rate was nearly the same as with the dry mid layer. A further consequence of the cooling effect of the wet clothing was the reduced sweat production, as it had been also reported with more permeable clothing (Cheuvront et al. 2007; Lotens and Havenith 1995), which in this experiment, however, did not result in significant differences in moisture evaporation to the environment, the latter most likely due to the limiting effect of the impermeable clothing layers used.

When comparing the human results to the manikin results, it should be noted that humans sweat and thus will increase the wetness of the initially dry inner underwear layer, while this would remain dry in the manikin testing. Thus in the experiments with wet $\mathrm{CO}$, for the humans the condition will be 'dry-wet' in the 
beginning and will slowly change towards 'wet-wet' when performing treadmill work, as it will with dry $\mathrm{CO}$ from 'dry-dry' towards 'wet-dry'. However, as the effect of wetting the outer cotton layer on the increase in heat loss and evaporated moisture was similar irrespective of the condition of the inner layer in the manikin tests, the observed parallel shift of skin and microclimate temperature in the human tests is in good agreement with the expectations from the manikin results.

\section{Clothing insulation from heat balance calculation}

The observed effects of the wet mid layer on microclimate and skin temperature in the human trials were reflected by a reduction of the $\mathrm{I}_{\mathrm{t}}$ values by 0.020 $\mathrm{m}^{2} \cdot{ }^{\circ} \mathrm{C} \cdot \mathrm{W}^{-1}(16 \%)$ only when calculated over the walking period, not when standing still, where $I_{t}$ remained nearly unchanged. This may be explained by the differences in evaporative cooling efficiency observed in the manikin experiments, that was nearly unity for the wet-wet condition corresponding to the walking condition in the human trials, but that was reduced to one third in the drywet condition, which is more representative for the humans standing still and hardly sweating. Re-calculating $\mathrm{I}_{\mathrm{t}}$ for the wet $\mathrm{CO}$ condition in the standing period, now allowing for the reduced evaporative cooling efficiency, yielded a mean (SD) insulation of $0.230(0.030) \mathrm{m}^{2} \cdot{ }^{\circ} \mathrm{C} \cdot \mathrm{W}^{-1}$, representing a reduction of 0.024 $\mathrm{m}^{2} \cdot{ }^{\circ} \mathrm{C} \cdot \mathrm{W}^{-1}(9 \%)$ compared to the dry $\mathrm{CO}$ condition. These relative reductions, especially those observed with the walking subjects, are somewhat higher than the values of $2-8 \%$ reported from manikin experiments (Chen et al. 2003), but are in line with those used in a recent modelling approach (Cheuvront et al. 2007). Compared to its static value, $\mathrm{I}_{\mathrm{t}}$ was reduced while walking by $50 \%$ with dry and by $59 \%$ with wet CO (54\% with the static value adjusted for evaporative cooling efficiency as described above), which exceeded the expected reduction due to body movements of 33\% that was calculated for the present walking speed applying correction equations (Havenith and Nilsson 2004). It should be noted that Havenith and Nilsson (2004) tested dry clothing only. The additional decrease in insulation observed here may reflect the wetting of the HHS and Tychem ${ }^{\circledR}$ layers due to sweating and, in case of the wetted mid layer, may also contain some added heat loss due to condensation in the outer layer (Lotens et al. 1995), as indicated by the higher moisture content accompanied by a tendency to increased surface temperature inside the PVC layer at the end of the experiment. 
As the impermeable separating layer utilised in the human trials proved to be an effective barrier to internal moisture transfer, evaporation-condensation cycles between the clothing layers appear to be of minor importance for the observed reduction in clothing insulation, as well as evaporation to the environment, because it was restricted by the choice of clothing and climatic condition. This leaves the increase in thermal conductivity of the wet clothing layers as the most probable explanation.

However, the manikin experiments indicate that (internal) evaporative heat transfer may have a larger impact on heat loss in wet clothing than increased conductivity. They also corroborate that considering the efficiency of evaporative cooling is crucial for the proper assessment of the heat transfer in protective clothing, especially when assessing the additional strain of working with protective clothing in the heat.

Projecting our observations, obtained under a temperate-humid climate, into the cold with a heavy physical workload in cold protective clothing, where only $10 \%$ of the produced sweat might evaporate to the environment (Meinander et al. 2004), it is suggested that sweat evaporation followed by re-condensation of moisture in the outer layers is mainly responsible for the reduced cold protection observed under these conditions.

\section{Conclusions}

To conclude, the human responses discussed above are symptomatic for a reduced insulation caused by the wet mid layer. As evaporation to the environment and inside the clothing was restricted, the increased conductivity of the wetted mid cotton layer is the most probable explanation for the observed alterations, which appear to be small compared to the effects associated with moisture evaporation. Together with other data emerging from the THERMPROTECT project, these findings may contribute to the development of models of the heat transfer through wet clothing.

\section{Acknowledgement}

This work was funded as European Union GROWTH programme project "THERMPROTECT, Assessment of Thermal Properties of Protective Clothing and Their Use", contract G6RD-CT2002-00846. 


\section{References}

Aoyagi Y, McLellan T, Shephard R (1996) Residual analysis in the determination of factors affecting the estimates of body heat storage in clothed subjects. Eur J Appl Physiol 73:287-298 DOI: $10.1007 / \mathrm{BF} 02425489$

Borg G (1998) Borg's Perceived Exertion and Pain Scales. Human Kinetics, Champaign, IL Candas V, Bröde P, Havenith G, THERMPROTECT network (2006) Classical approach to heat and vapour resistance calculations cannot explain heat transfer in wet clothing. In: Fan J (ed) Thermal manikins and modelling. The Hong Kong Polytechnic University, Hong Kong, pp 235246

Chen YS, Fan J, Zhang W (2003) Clothing thermal insulation during sweating. Text Res J 73:152157

Cheuvront SN, Montain SJ, Goodman DA, Blanchard L, Sawka MN (2007) Evaluation of the limits to accurate sweat loss prediction during prolonged exercise. Eur J Appl Physiol 101:215-224 DOI: $10.1007 / \mathrm{s} 00421-007-0492-\mathrm{x}$

Craig FN, Moffitt JT (1974) Efficiency of evaporative cooling from wet clothing. J Appl Physiol 36:313-316

DIN 50010-2 (1981) Klimate und ihre technische Anwendung, Klimabegriffe, Physikalische Begriffe. Beuth Verlag, Berlin

Havenith G, Holmér I, Meinander H, den Hartog EA, Richards M, Bröde P, Candas V (2005) THERMPROTECT. Assessment of thermal properties of protective clothing and their use. Summary Technical Report European Union Contract Nº G6RD-CT-2002-00846 (accessible at http://www.lboro.ac.uk/departments/hu/groups/htel/THERMPROTECT/THERMPROTECT\%20re port\%201.htm)

Havenith G, Nilsson HO (2004) Correction of clothing insulation for movement and wind effects, a meta-analysis. Eur J Appl Physiol 92:636-640

Havenith G, Richards M, Wang X, Bröde P, Candas V, den Hartog EA, Holmér I, Kuklane K, Meinander H, Nocker W (2007a) Apparent latent heat of evaporation from clothing: attenuation and 'heat pipe' effects. J Appl Physiol under revision

Havenith G, Wang X, Richards M, Bröde P, Candas V, den Hartog E, Holmér I, Meinander H, Nocker W (2006) Evaporative cooling in protective clothing, In: European Society of Protective Clothing (ed) 3rd European conference on protective clothing. Central Institute for Labour Protection - National Research Institute, Warszawa, ISBN: 83-7373-097-4 (CD-ROM, 6 pp) Havenith G, Wang X, Richards M, Candas V, Meinander H, Broede P, den Hartog EA, Holmér I, Nocker W (2007b) Apparent and real cooling efficiency of moisture evaporation from the skin while wearing protective clothing. J Physiol Anthropol 26:272-273

ISO 10551 (1995) Ergonomics of the thermal environment - Assessment of the influence of the thermal environment using subjective judgement scales. International Organisation for Standardisation, Geneva

ISO 15831 (2004) Clothing. Physiological effects. Measurement of thermal insulation by means of a thermal manikin. International Organisation for Standardisation, Geneva 
ISO 8996 (2004) Ergonomics of the thermal environment - Determination of metabolic rate. International Organisation for Standardisation, Geneva

ISO 9886 (1992) Evaluation of thermal strain by physiological measurements. International Organisation for Standardisation, Geneva

ISO 9920 (2007) Ergonomics of the thermal environment - Estimation of thermal insulation and water vapour resistance of a clothing ensemble. International Organisation for Standardisation, Geneva

Lotens WA, Havenith G (1995) Effects of moisture absorption in clothing on the human heat balance. Ergonomics 38:1092-1113

Lotens WA, van de Linde FJ, Havenith G (1995) Effects of condensation in clothing on heat transfer. Ergonomics 38:1114-1131

Malchaire J, Piette A, Kampmann B, Mehnert P, Gebhardt H, Havenith G, den Hartog EA, Holmér I, Parsons K, Alfano G, Griefahn B (2001) Development and validation of the predicted heat strain model. Ann Occup Hyg 45:123-135

McCullough EA, Huang J, Deaton S (2005) Methods for measuring the clothing area factor. In: Holmér I, Kuklane K, Gao C (eds) Environmental ergonomics XI. Lund University, pp 433-436 McLellan T, Pope J, Cain J, Cheung S (1996) Effects of metabolic rate and ambient vapour pressure on heat strain in protective clothing. Eur J Appl Physiol 74:518-527 DOI:

10.1007/BF02376767

Meinander H, Anttonen H, Bartels V, Holmér I, Reinertsen RE, Soltynski K, Varieras S (2004) Manikin measurements versus wear trials of cold protective clothing (subzero project). Eur J Appl Physiol 92:619-621

Nunneley SA (1989) Heat stress in protective clothing. Interactions among physical and physiological factors. Scand J Work Environ Health 15 Suppl 1:52-57 


\section{Tables}

Table 1: Means (SD) of sweat production, moisture content in the clothing after the experiment and clothed mass loss for the three 30 min periods in human trials with dry and wet CO mid layer.

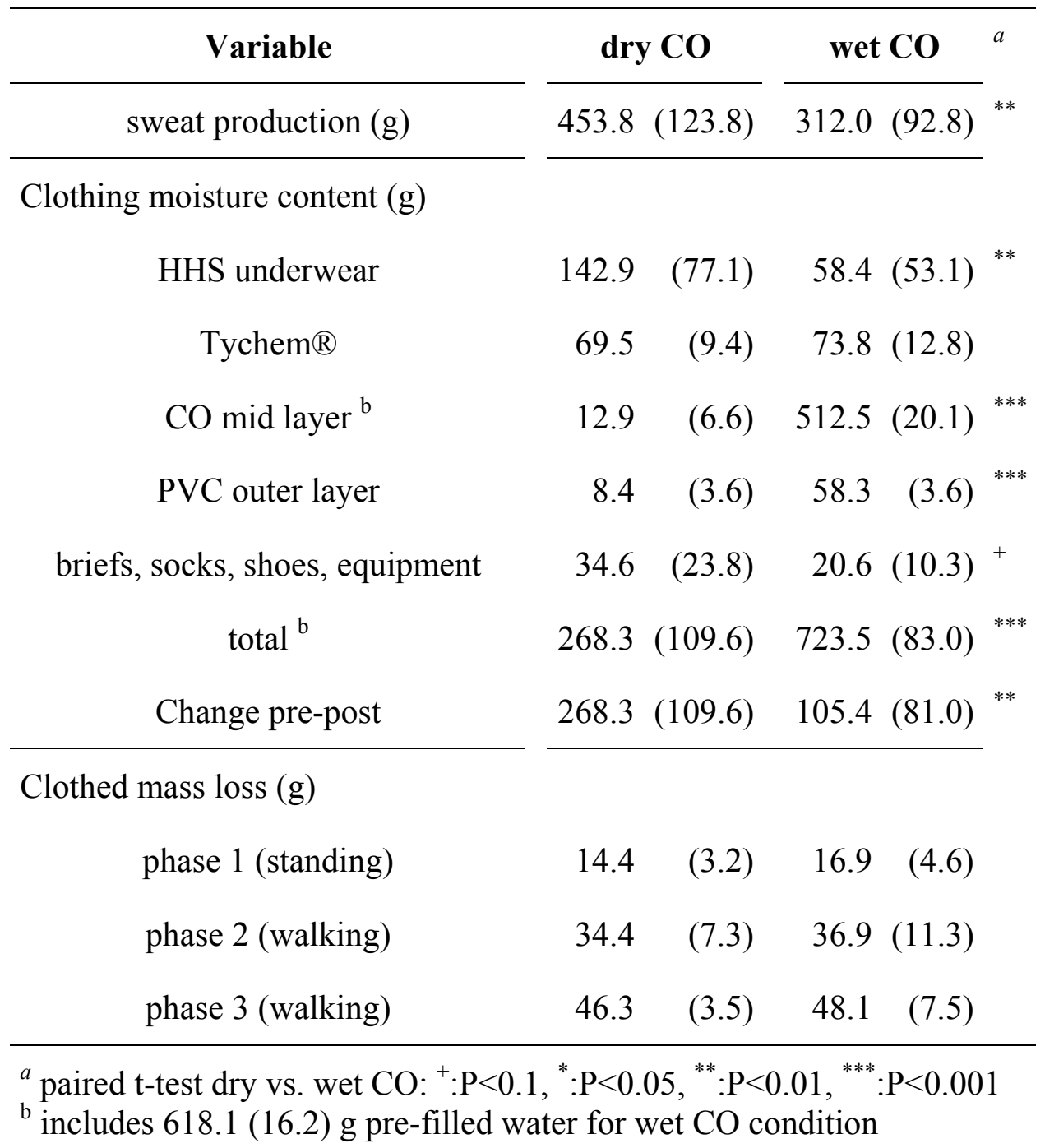


Table 2: Means (SD) of clothing microclimate data, physiological and subjective responses (cf. text for abbreviations) at the end of standing and walking phases in human trials with dry and wet CO mid layer.

\begin{tabular}{|c|c|c|c|c|c|c|}
\hline \multirow[t]{2}{*}{ Variable } & \multicolumn{3}{|c|}{ standing (phase 1) } & \multicolumn{3}{|c|}{ walking (phase 3) } \\
\hline & dry CO & wet $\mathrm{CO}$ & $a$ & dry CO & wet $\mathrm{CO}$ & $a$ \\
\hline \multicolumn{7}{|c|}{ Clothing microclimate HHS/Tychem ${ }^{\circledR}$ layer } \\
\hline $\mathrm{T}_{\mathrm{mc}}\left({ }^{\circ} \mathrm{C}\right)$ & $30.9(0.6)$ & $29.7(0.6)$ & ** & $33.8(0.4)$ & $32.2(0.6)$ & *** \\
\hline $\mathrm{RH}_{\mathrm{mc}}(\%)$ & $80.0(3.4)$ & $79.3(3.1)$ & & $95.7(1.3)$ & $95.0(1.1)$ & \\
\hline $\mathrm{P}_{\mathrm{mc}}(\mathrm{kPa})$ & $3.6(0.2)$ & $3.3(0.1)$ & $*$ & $5.0(0.1)$ & $4.6(0.1)$ & $* * *$ \\
\hline
\end{tabular}

Clothing microclimate $\mathrm{CO} / \mathrm{PVC}$ layer

$\begin{array}{crrrrrrr}\mathrm{T}_{\mathrm{mc}}\left({ }^{\circ} \mathrm{C}\right) & 26.6(0.4) & 26.5(0.7) & & 28.9(0.4) & 28.4(0.7) \\ \mathrm{RH}_{\mathrm{mc}}(\%) & 47.6(4.9) & 91.3(0.9) & { }^{* * *} & 49.5(4.1) & 93.8(1.2) \\ \mathrm{P}_{\mathrm{mc}}(\mathrm{kPa}) & 1.7(0.2) & 3.2(0.1) & { }^{* * *} & 2.0(0.2) & 3.6(0.1)\end{array}$ *** $^{* * *}$

PVC layer surface temperature

\begin{tabular}{|c|c|c|c|c|c|}
\hline inside $\left({ }^{\circ} \mathrm{C}\right)$ & $23.3(0.6)$ & $23.4(0.4)$ & & $25.0(0.6)$ & $25.4(0.7)$ \\
\hline outside $\left({ }^{\circ} \mathrm{C}\right)$ & $23.7(0.3)$ & $23.8(0.4)$ & & $25.6(0.4)$ & $25.8(0.7)$ \\
\hline $\mathrm{HR}\left(\mathrm{min}^{-1}\right)$ & $78.0(13.2)$ & $76.9(10.8)$ & & $106.1(10.5)$ & $98.6(9.9)$ \\
\hline $\mathrm{T}_{\mathrm{re}}\left({ }^{\circ} \mathrm{C}\right)$ & $37.0(0.2)$ & $37.0(0.3)$ & & $37.5(0.2)$ & $37.4(0.3)$ \\
\hline $\mathrm{T}_{\mathrm{sk}}\left({ }^{\circ} \mathrm{C}\right)$ & $33.2(0.5)$ & $32.6(0.5)$ & *** & $34.9(0.4)$ & $33.7(0.4)$ \\
\hline
\end{tabular}

Subjective responses

\begin{tabular}{|c|c|c|c|c|}
\hline $\mathrm{TS}$ & $1.0(0.5)$ & $0.4(0.9)$ & $2.5(0.5)$ & $2.3(0.7)$ \\
\hline $\mathrm{TP}$ & $0.5(0.5)$ & $-0.1(0.4)$ & $1.6(0.9)$ & $1.4(0.7)$ \\
\hline $\mathrm{TT}$ & $1.6(0.7)$ & $1.4(0.7)$ & $3.1(1.4)$ & $2.6(1.3)$ \\
\hline MS & $1.6(0.7)$ & $1.6(1.1)$ & $3.9(0.8)$ & $3.6(1.1)$ \\
\hline RPE & 10.1 & 10.3 & 14.5 & 14.0 \\
\hline
\end{tabular}


Table 3: Means (SD) of heat balance components (cf. text for abbreviations) and total clothing insulation $\left(\mathrm{I}_{\mathrm{t}}\right)$ for phase 1 and 3 in the human trials with dry and wet CO mid layer.

\begin{tabular}{|c|c|c|c|c|c|c|c|c|c|}
\hline \multirow[t]{2}{*}{ Variable } & \multicolumn{4}{|c|}{ standing (phase 1) } & \multicolumn{5}{|c|}{ walking (phase 3) } \\
\hline & \multicolumn{2}{|c|}{ dry CO } & \multicolumn{2}{|c|}{ wet CO } & \multicolumn{2}{|c|}{ dry CO } & \multicolumn{3}{|c|}{ wet CO } \\
\hline \multicolumn{10}{|c|}{ Heat balance components $\left(\mathrm{W} \mathrm{m}^{-2}\right)^{\mathrm{b}}$} \\
\hline M & 60.7 & (11.9) & 60.2 & $(11.5)$ & 173.6 & $(11.5)$ & 175.8 & $(10.0)$ & \\
\hline $\mathrm{S}$ & -3.2 & $(7.4)$ & -3.0 & $(12.0)$ & 18.8 & $(11.5)$ & 7.8 & $(13.3)$ & * \\
\hline $\mathrm{E}$ & 6.3 & $(1.9)$ & 8.1 & $(3.0)$ & 21.5 & (3.6) & 22.6 & (4.4) & \\
\hline $\mathrm{E}_{\text {resp }}$ & 3.7 & $(0.7)$ & 3.7 & $(0.7)$ & 10.6 & $(0.7)$ & 10.8 & $(0.6)$ & \\
\hline $\mathrm{C}_{\text {resp }}$ & 1.1 & $(0.2)$ & 1.1 & $(0.2)$ & 3.2 & $(0.2)$ & 3.2 & $(0.2)$ & \\
\hline Dry & 52.8 & $(7.3)$ & 50.3 & $(6.5)$ & 119.5 & $(16.1)$ & 131.4 & $(15.6)$ & \\
\hline \multicolumn{10}{|c|}{ Clothing insulation $\left(\mathrm{m}^{2}{ }^{\circ} \mathrm{C} \mathrm{W}^{-1}\right)$} \\
\hline $\mathrm{I}_{\mathrm{t}}$ & 0.254 & $(0.030)$ & 0.256 & $(0.040)$ & 0.126 & $(0.016)$ & 0.106 & $(0.014)$ & * \\
\hline
\end{tabular}




\section{Legends}

Figure 1: Total manikin heat loss for the four conditions, and the heat loss expressed as increase from dry-dry, i.e. apparent evaporative heat loss, as well as the evaporative loss calculated from weight change.

Figure 2: Mass losses (negative values) and gains for the different layers, as well as amount evaporated during the manikin measurements with wet $\mathrm{CO}$ layers.

Figure 3: Means and SD of the clothing microclimate temperature, relative humidity and partial water vapour pressure measured between the underwear and the separating layer (layer \#1-2, circles), and between the mid CO and the PVC outer layer (layer \#3-4, triangles) in the human trials with dry (open symbols, upper error bars) and wet (filled symbols, lower error bars) mid CO layer.

Figure 4: Means and SD of heart rate, rectal and mean skin temperature in the human trials with dry (open symbols, upper error bars) and wet (filled symbols, lower error bars) CO mid layer. 


\section{Illustrations}

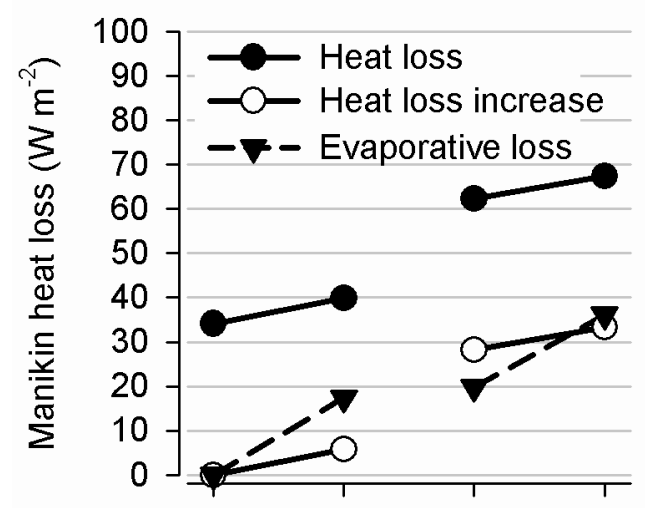

dry-dry dry-wet wet-dry wet-wet

condition of $\mathrm{CO}$ layers

Figure 1: Total manikin heat loss for the four conditions, and the heat loss expressed as increase from dry-dry, i.e. apparent evaporative heat loss, as well as the evaporative loss calculated from weight change.

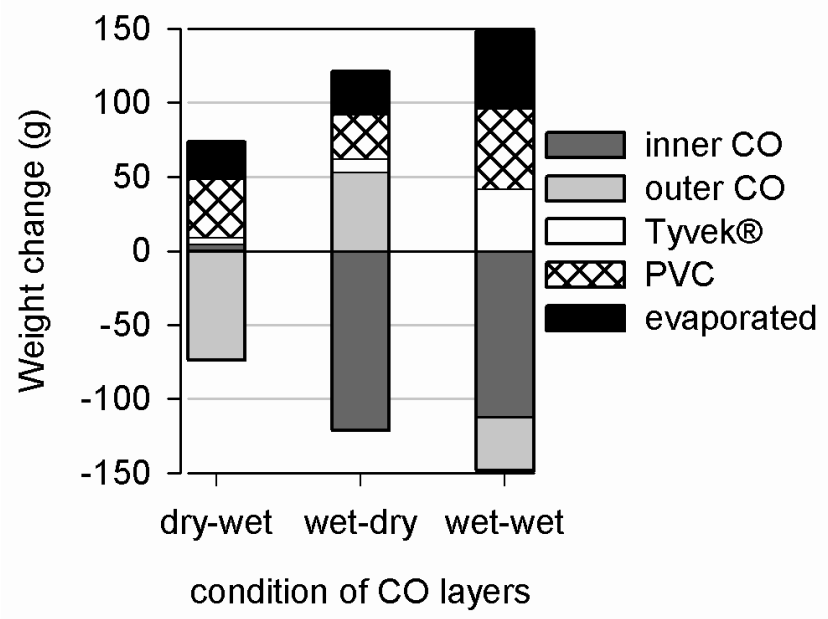

Figure 2: Mass losses (negative values) and gains for the different layers, as well as amount evaporated during the manikin measurements with wet $\mathrm{CO}$ layers. 

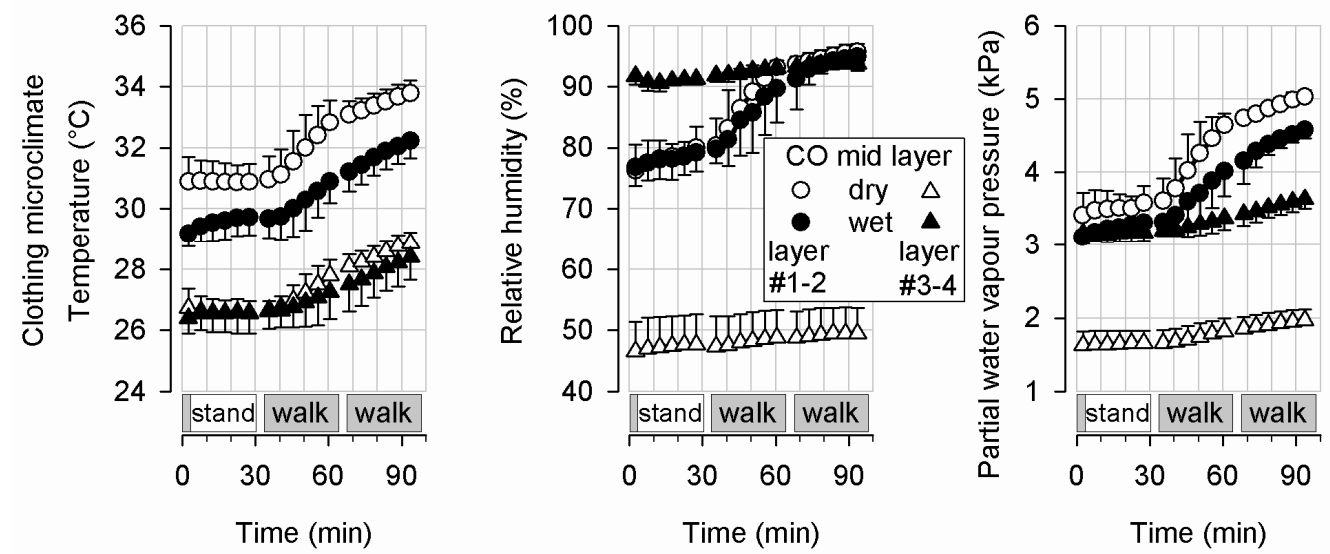

Figure 3: Means and SD of the clothing microclimate temperature, relative humidity and partial water vapour pressure measured between the underwear and the separating layer (layer \#1-2, circles), and between the mid CO and the PVC outer layer (layer \#3-4, triangles) in the human trials with dry (open symbols, upper error bars) and wet (filled symbols, lower error bars) mid CO layer.
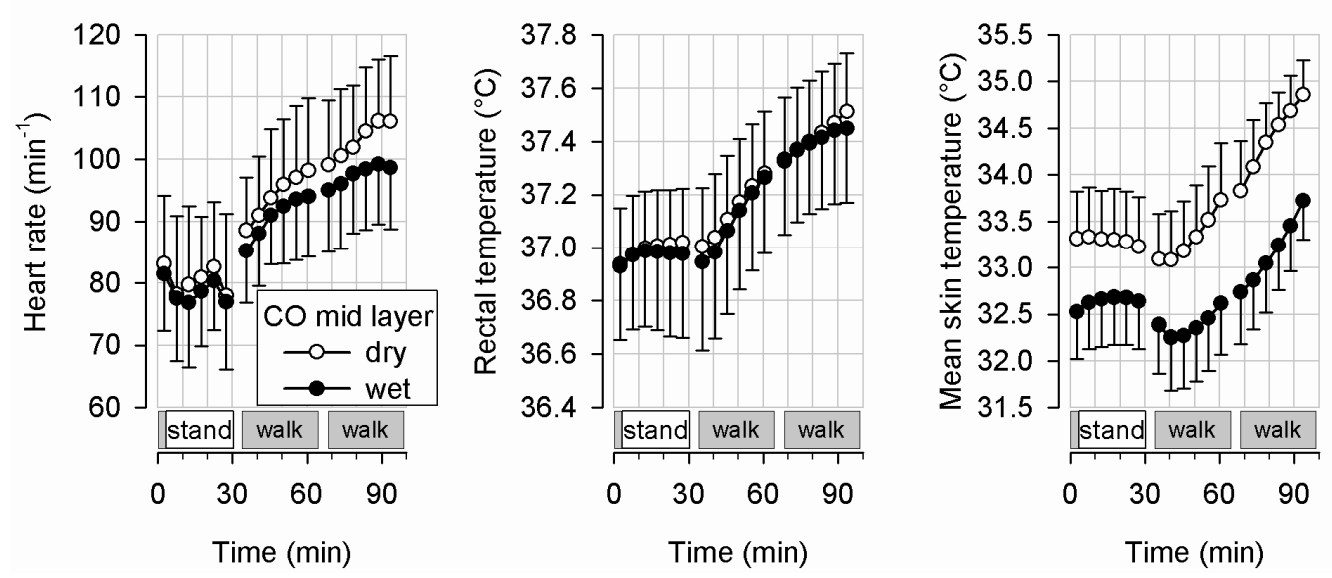

Figure 4: Means and SD of heart rate, rectal and mean skin temperature in the human trials with dry (open symbols, upper error bars) and wet (filled symbols, lower error bars) CO mid layer. 